\title{
Nucleophilic fluoroalkylation/cyclization route to fluorinated phthalides
}

\author{
Masanori Inaba ${ }^{1}$, Tatsuya Sakai ${ }^{1}$, Shun Shinada ${ }^{1}$, Tsuyuka Sugiishi ${ }^{1}$, Yuta Nishina ${ }^{2}$, \\ Norio Shibata ${ }^{3}$ and Hideki Amii ${ }^{* 1}$
}

\section{Full Research Paper}

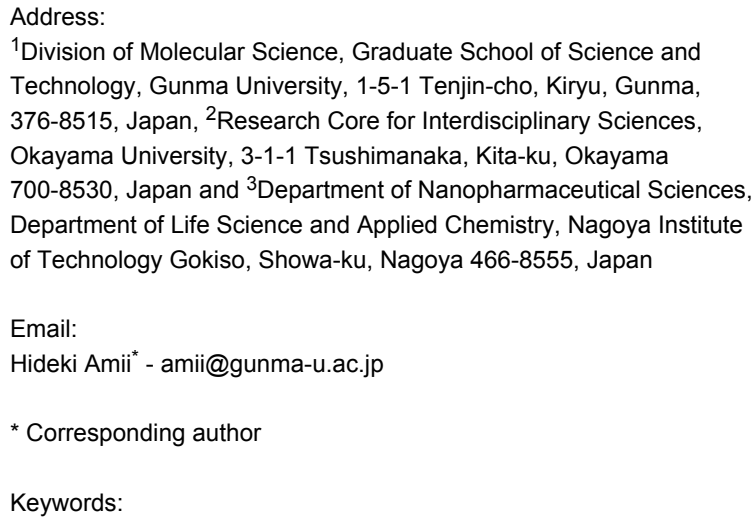

${ }^{1}$ Division of Molecular Science, Graduate School of Science and Technology, Gunma University, 1-5-1 Tenjin-cho, Kiryu, Gunma, 376-8515, Japan, ${ }^{2}$ Research Core for Interdisciplinary Sciences, Okayama University, 3-1-1 Tsushimanaka, Kita-ku, Okayama 700-8530, Japan and ${ }^{3}$ Department of Nanopharmaceutical Sciences, Department of Life Science and Applied Chemistry, Nagoya Institute of Technology Gokiso, Showa-ku, Nagoya 466-8555, Japan

Email:

Hideki Amii* - amii@gunma-u.ac.jp

* Corresponding author

Keywords:

cyclization; fluorine; lactone; phthalide; trifluoromethylation

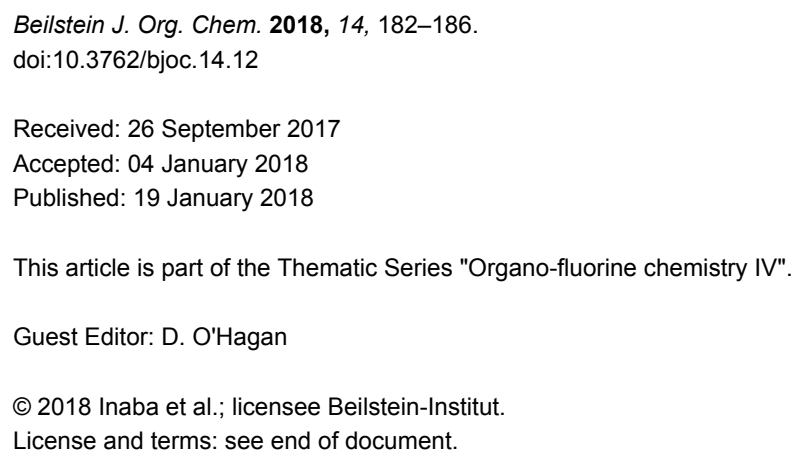

\begin{abstract}
Discribed in this article is a versatile and practical method for the synthesis of C3-perfluoroalkyl-substituted phthalides in a one-pot manner. Upon treatment of KF or triethylamine, 2-cyanobenzaldehyde reacted with (perfluoroalkyl)trimethylsilanes via nucleophilic addition and subsequent intramolecular cyclization to give perfluoroalkylphthalides in good yields.
\end{abstract}

\section{Introduction}

Phthalides (1(3H)-isobenzofuranones) are frequently found in natural products and exhibit a range of bioactivity (Scheme 1) $[1,2]$. Substituted phthalides have been used as building blocks for the synthesis of useful bioactive compounds. There is a growing interest in the usefulness of phthalides and their derivatives. Organofluorine compounds often show attractive physical, chemical, and biological properties and are widely used in many fields, such as pharmaceuticals, agrochemicals, and materials [3-10]. Selective incorporation of fluorine or a fluoroalkyl group into a molecule is a topic of significant interest in organic chemistry. Fluorinated phthalides are considered to be one of the most fascinating organofluorine compounds. However, to our best knowledge, there have been few reports on the preparation of fluoroalkyl phthalides [11-19]. The first synthesis of 3-(trifluoromethyl)phthalides was accomplished by Reinecke and Chen in 1993. They studied ortho-lithiation of phenyloxazolines and the subsequent reactions with pentafluoroacetone and hexafluoroacetone to give 3-(trifluoromethyl)phthalide derivatives [11]. In 2006, Pedrosa et al. reported the nucleophilic trifluoromethylation of protected ortho-phthalaldehyde, followed by deprotection and oxidation to afford 3-(trifluoromethyl)phthalide [12]. Pohmakotr et al. demonstrated the nucleophilic trifluoromethylation of acid anhydrides to produce $\gamma$-hydroxy- $\gamma$-trifluoromethyl- $\gamma$-butyrolactones, which acted as 
good precursors in the synthesis of $\gamma$-trifluoromethyl- $\gamma$-butyrolactones with organometallic reagents [16]. All these protocols involve multiple steps to obtain trifluoromethylphthalides. An operational simple procedure for a short-step synthesis of 3-(trifluoromethyl)phthalide is required due to their great potential in a variety of applications. Herein, we wish to report a general and convenient synthesis of 3-(perfluoroalkyl)phthalides $\mathbf{1}$ by nucleophilic perfluoroalkylation of 2-cyanobenzaldehyde (2) and subsequent intramolecular cyclization.<smiles>O=C1CCc2ccccc21</smiles>

phthalide<smiles>[R7]C1OC(=O)c2ccccc21</smiles>

1

$\left(\mathrm{R}_{\mathrm{F}}=\mathrm{CF}_{3}, \mathrm{C}_{2} \mathrm{~F}_{5}\right.$, etc. $)$
Scheme 1: Phthalide and fluorinated phthalides (1)

\section{Results and Discussion}

The reaction procedure is very simple. A mixture of 2-cyanobenzaldehyde (2), $\mathrm{CF}_{3}-\mathrm{SiMe}_{3}$ (so-called Ruppert-Prakash reagent) [20,21], and a catalytic amount of $\mathrm{KF}$ in anhydrous DMF was stirred at room temperature for $1 \mathrm{~h}$. After work-up under acidic conditions, 3-(trifluoromethyl)-1(3H)-isobenzofuranone (1a) was obtained in 99\% NMR yield (95\% isolated yield) (Table 1, entry 1). As a good alternative activator of $\mathrm{CF}_{3}-\mathrm{SiMe}_{3}$, the use of a Lewis base such as triethylamine $[22,23]$ worked well for the synthesis of 3-(trifluoromethyl)phthalide (1a, Table 1, entries 2-4). When aldehyde 2 was treated with $\mathrm{CF}_{3}-\mathrm{SiMe}_{3}$ in the presence of $\mathrm{Et}_{3} \mathrm{~N}$ at $50{ }^{\circ} \mathrm{C}$, the cascade trifluoromethylation/cyclization proceeded smoothly to afford phthalide 1a in 70\% isolated yield (Table 1, entry 4).

Table 1: Trifluoromethylation/cyclization of 2-cyanobenzaldehyde.<smiles>N#Cc1ccccc1C=O</smiles>

2

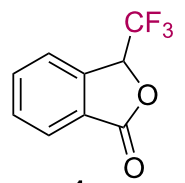

$1 \mathrm{a}$

\begin{tabular}{llll}
\hline Entry & Base (equiv) & Conditions & Yield of 1a (\%) ${ }^{\mathrm{a}, \mathrm{b}}$ \\
\hline 1 & $\mathrm{KF}(0.1)$ & $\mathrm{rt}, 1 \mathrm{~h}$ & $99(95)$ \\
2 & $\mathrm{Et}_{3} \mathrm{~N}(0.5)$ & $\mathrm{rt}, 1 \mathrm{~h}$ & 80 \\
3 & $\mathrm{Et}_{3} \mathrm{~N}(0.5)$ & $50^{\circ} \mathrm{C}, 1 \mathrm{~h}$ & 86 \\
4 & $\mathrm{Et}_{3} \mathrm{~N}(1.0)$ & $50^{\circ} \mathrm{C}, 1 \mathrm{~h}$ & $91(70)$ \\
\hline
\end{tabular}

ayields were determined by ${ }^{19} \mathrm{~F}$ NMR analysis using 1,3-bis(trifluoromethyl)benzene as an internal standard. ${ }^{\mathrm{b}}$ The values in parentheses indicate the isolated yield of $1 \mathrm{a}$.
The formation of phthalide 1a can be explained by assuming the pathway shown in Scheme 2. The formyl group in aldehyde $\mathbf{2}$ undergoes nucleophilic trifluoromethylation triggered by a catalytic amount of KF to give the ortho-cyanobenzyl silyl ether $\mathbf{3}$. Upon treatment with aq $\mathrm{HCl}$, the subsequent lactonization of $\mathbf{4}$ takes place to afford trifluoromethylphthalide $\mathbf{1 a}$.<smiles>COC(c1ccccc1C#N)C(C)(C)CC(C)(C)C(F)(F)F</smiles>

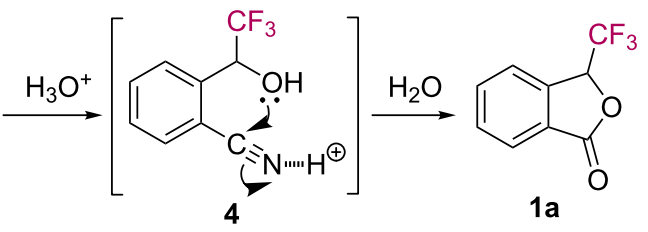

Scheme 2: Plausible reaction mechanism for the formation of phthalide $1 \mathrm{a}$.

Other examples of the one-pot synthesis of fluorinated phthalides 1 are given in Scheme 3. The reactions of 2-cyanobenzaldehyde (2) with organosilicon compounds $\left(\mathrm{R}_{\mathrm{F}}-\mathrm{SiMe}_{3}\right)$ proceeded cleanly by the use of KF (conditions A) or $\mathrm{Et}_{3} \mathrm{~N}$ (conditions B). As a consequence, pentafluoroethyl, heptafluo-

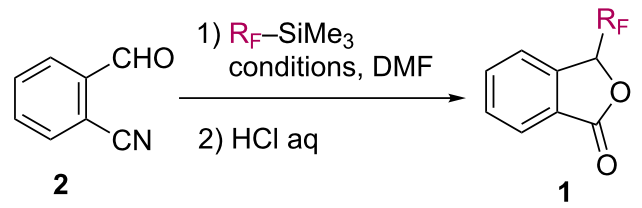<smiles>O=C1OC(C(F)(F)F)c2ccccc21</smiles>

1a: $95 \%$ (conditions A) $70 \%$ (conditions B)<smiles>O=C1OC(C(F)(F)C(F)(F)C(F)(F)F)c2ccccc21</smiles>

1c: $38 \%$ (conditions $A$ ) $60 \%$ (conditions B)<smiles>O=C1OC(C(F)(F)F)c2ccccc21</smiles>

1b: $77 \%$ (conditions A) $68 \%$ (conditions $\mathrm{B}$ )<smiles>O=C1OC(c2c(F)c(F)c(F)c(F)c2F)c2ccccc21</smiles>

1d: $86 \%$ (conditions A) $63 \%$ (conditions B) 
ropropyl, and pentafluorophenyl $[24,25]$ groups were successfully installed at the C3-position of phthalides $\mathbf{1 b}-\mathbf{d}$.

Thus, the selective formation of fluorinated phthalides 1 represents a synthetic usefulness for further applications. In particular, the asymmetric synthesis of C3-substituted phthalides is of considerable importance in chemistry [26-32]. Enantioselective fluoroalkylation/lactonization reactions are worth investigating since a new stereogenic carbon center next to the fluoroalkyl groups is generated in products $\mathbf{1}$. To the best of our knowledge, only one successful example of an asymmetric synthesis of 3-(trifluoromethyl)phthalide (1a) using a chiral auxiliary was published to date. In 2006, Pedrosa and co-workers discribed the diastereoselective nucleophilic trifluoromethylation of aldehyde 5 , which was prepared by condensation of ortho-phthalaldehyde with (-)-8-benzylaminomenthol (Scheme 4) [12]. Only diastereoisomer 6 was detected in the NMR analysis. Acid-promoted deprotection of hemiaminal $\mathbf{6}$ and subsequent oxidation of acetal 7 gave the enantiopure phthalide 1a in good yield.

Although a high control of diastereoselectivity (using stoichiometric auxiliary strategy) was achieved for the asymmetric syn-

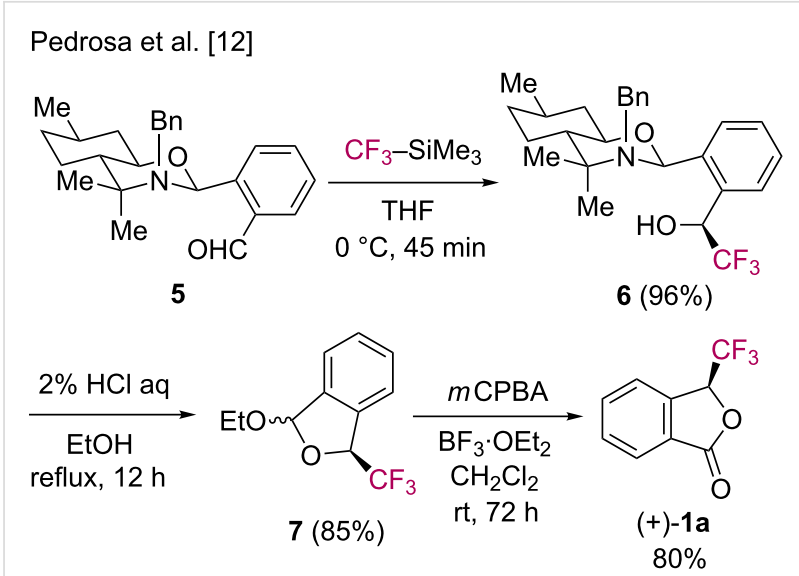

Scheme 4: Asymmetric synthesis of 1a using a chiral auxiliary.

thesis of trifluoromethylphthalide 1a, it is desirable to reduce the amount of the chiral sources. Next, we undertook the development of a catalytic asymmetric synthesis of $\mathbf{1}$ in a one-pot manner. The results of our trial are summarized in Table 2.

For the catalytic asymmetric synthesis of $\mathbf{1}$, we carried out the nucleophilic trifluoromethylation of $\mathbf{2}$ employing a small

Table 2: Trifluoromethylation/cyclization of 2-cyanobenzaldehyde (2) in the presence of chiral catalysts.
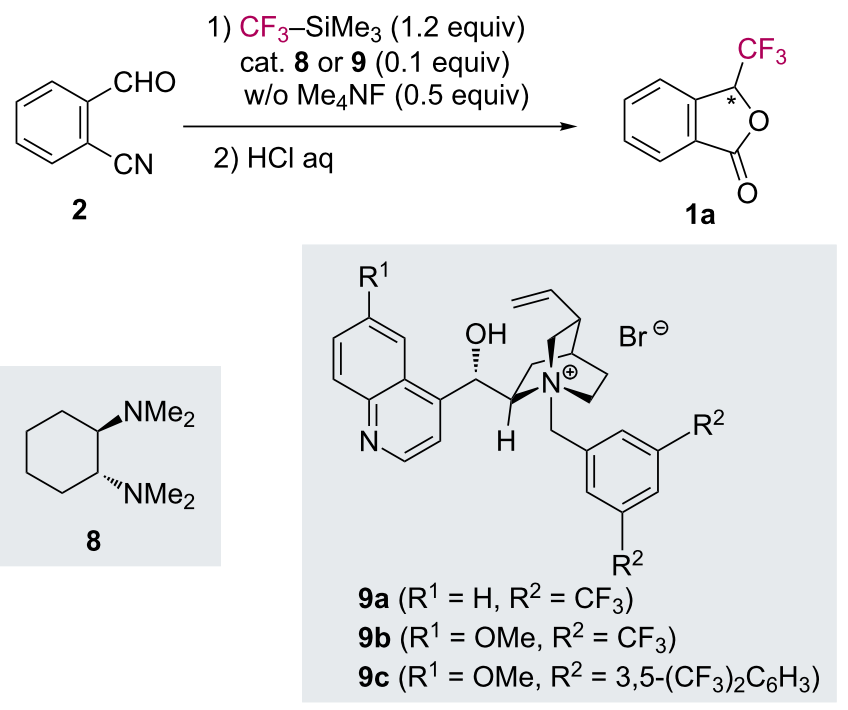

\begin{tabular}{|c|c|c|c|c|c|}
\hline Entry & Catalyst & Solvent & Conditions & Yield of $1 \mathbf{a}(\%)^{a}$ & $\% \mathrm{ee}^{\mathrm{b}}$ \\
\hline 1 & 8 & DMF & $\mathrm{rt}, 1 \mathrm{~h}$ & 79 & 0 \\
\hline 2 & 8 & DMF & $0{ }^{\circ} \mathrm{C}, 1 \mathrm{~h}$ & 62 & 0 \\
\hline 3 & $9 a$ & toluene $/ \mathrm{CH}_{2} \mathrm{Cl}_{2}(2: 1)$ & $-60{ }^{\circ} \mathrm{C}, 24 \mathrm{~h}$ & 61 & 0 \\
\hline 4 & $9 b$ & toluene $/ \mathrm{CH}_{2} \mathrm{Cl}_{2}(2: 1)$ & $-60^{\circ} \mathrm{C}, 24 \mathrm{~h}$ & 51 & 12 \\
\hline 5 & $9 c$ & toluene $/ \mathrm{CH}_{2} \mathrm{Cl}_{2}(2: 1)$ & $-60{ }^{\circ} \mathrm{C}, 24 \mathrm{~h}$ & 76 & 6 \\
\hline
\end{tabular}

alsolated yield of $1 \mathrm{a} .{ }^{\mathrm{b}}$ Each enantiomeric excess (ee) was determined by HPLC analyses. 
amount of chiral tertiary amines. However, the use of $(1 R, 2 R)$ ( $N, N, N$ ', $N$ '-tetramethyl)-1,2-diaminocyclohexane (8) as a chiral catalyst resulted in the formation of a racemic mixture of $\mathbf{1 a}$ (Table 2, entries 1 and 2).

Previously, Shibata et al. reported a cinchona alkaloid/Me $\mathrm{MNF}_{4} \mathrm{~N}$ catalyzed nucleophilic enantioselective trifluoromethylation of carbonyl compounds [33-35]. Initially, we tried to conduct the reaction of 2-cyanobenzaldehyde (2) with $\mathrm{CF}_{3}-\mathrm{SiMe}_{3}$ in the presence of cinchona alkaloids 9/TMAF combination (Table 2 , entries 3-5). By employing catalyst $\mathbf{9 b}$, the reaction proceeded at $-60{ }^{\circ} \mathrm{C}$ to give phthalide $1 \mathrm{a}$ in $51 \%$ yield with $12 \%$ ee (Table 2, entry 4 ).

To improve the enantioselectivity of the present nucleophilic trifluorometylation/lactonization, we surveyed suitable conditions for the catalytic asymmetric transformation. After many experiments, we found that the use of ethyl 2-formylbenzoate (10) [36] instead of nitrile 2 resulted in the formation of 1 a with $27 \%$ ee upon exposure to organocatalyst $9 \mathbf{b}$ ( 0.1 equiv) and tetramethylammonium fluoride ( 0.5 equiv, Scheme 5$)$.

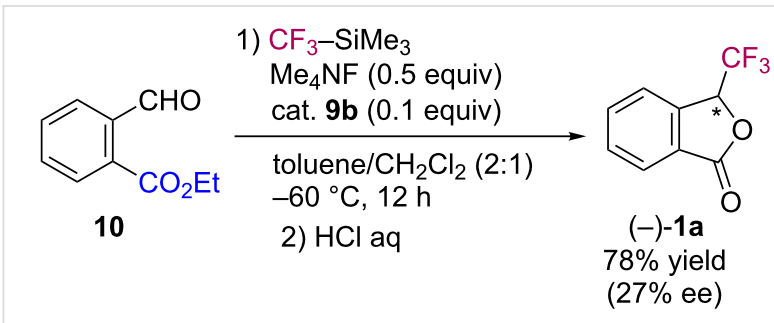

Scheme 5: Catalytic asymmetric synthesis of $1 \mathrm{a}$.

\section{Conclusion}

In summary, we have demonstrated a convenient route to fluorinated phthalides from 2-cyanobenzaldehyde or 2-formylbenzoates in a one-pot manner. In the transformations, installation of fluorinated substituents at the C3-position of phthalides has been achieved. The issue of the low stereoselectivity of the catalytic asymmetric fluoroalkylation should be solved in the future. Further examples for the promising utilization of fluorinated phthalides as building blocks can be found in [37].

\section{Supporting Information}

\section{Supporting Information File 1}

General methods, synthetic procedures, ${ }^{1} \mathrm{H}$ and ${ }^{19} \mathrm{~F}$ NMR spectra for known compound 1a and full characterization of all new compounds.

[https://www.beilstein-journals.org/bjoc/content/ supplementary/1860-5397-14-12-S1.pdf]

\section{Acknowledgements}

This article is dedicated to the memory of Professor Yoshihiko Ito (1937-2006) on the occasion of the 10th anniversary of his sudden death. The financial support of JSPS KAKENHI Grant No. JP 16H04143 (Grant-in-Aid for Scientific Research (B)), JP16H01003 in Precisely Designed Catalysts with Customized Scaffolding, JP16H01129 in Middle Molecular Strategy, and Japan Science and Technology Agency (JST) (ACT-C: Creation of Advanced Catalytic Transformation for the Sustainable Manufacturing at Low Energy, Low Environmental Load) is acknowledged. We would like to thank Prof. Hiroshi Sano (Gunma University) for his useful suggestions.

\section{ORCID ${ }^{\circledR} \mathrm{iDs}$}

Norio Shibata - https://orcid.org/0000-0002-3742-4064

\section{References}

1. Lin, G.; Chan, S.-K. S.; Chung, H.-S.; Li, S.-L. Chemistry and biological activities of naturally occurring phthalides. In Studies in Natural Products Chemistry; Atta-ur-Rahman, Ed.; Elsevier: Amsterdam, 2005; Vol. 32, pp 611-670.

2. Knepper, K.; Ziegert, R. E.; Bräse, S. Tetrahedron 2004, 60, 8591-8603. doi:10.1016/j.tet.2004.05.111

3. Hiyama, T.; Kanie, K.; Kusumoto, T.; Morizawa, Y.; Shimizu, M. In Organofluorine Compounds: Chemistry and Applications; Yamamoto, H., Ed.; Springer-Verlag: Berlin, 2000. doi:10.1007/978-3-662-04164-2

4. Kirsch, P. Modern Fluoroorganic Chemistry: Synthesis, Reactivity, Applications; Wiley-VCH: Weinheim, Germany, 2004. doi:10.1002/352760393X

5. Chambers, R. D. Fluorine in Organic Chemistry; Blackwell: Oxford, 2004.

6. Uneyama, K. Organofluorine Chemistry; Blackwell: Oxford, 2006.

7. Bégué, J.-P.; Bonnet-Delpon, D. Bioorganic and Medicinal Chemistry of Fluorine; John Wiley \& Sons, Inc.: Hoboken, NJ, 2008. doi:10.1002/9780470281895

8. Ojima, I., Ed. Fluorine in Medicinal Chemistry and Chemical Biology; Wiley-Blackwell: Chichester, West Sussex, 2009. doi:10.1002/9781444312096

9. Fluorine in Pharmaceutical and Medicinal Chemistry: From Biophysical Aspects to Clinical Applications; Gouverneur, V.; Müller, K., Eds.; Molecular Medicine and Medicinal Chemistry, Vol. 6; Imperial College Press: London, 2012. doi:10.1142/p746

10. Wang, J.; Sánchez-Roselló, M.; Aceña, J. L.; del Pozo, C.; Sorochinsky, A. E.; Fustero, S.; Soloshonok, V. A.; Liu, H. Chem. Rev. 2014, 114, 2432-2506. doi:10.1021/cr4002879

11. Reinecke, M. G.; Chen, L.-J. Acta Chem. Scand. 1993, 47, 318-322. doi:10.3891/acta.chem.scand.47-0318

12. Pedrosa, R.; Sayalero, S.; Vicente, M. Tetrahedron 2006, 62, 10400-10407. doi:10.1016/j.tet.2006.08.058

13. Zonov, Y. V.; Karpov, V. M.; Platonov, V. E.; Rybalova, T. V.; Gatilov, Y. V. J. Fluorine Chem. 2006, 127, 1574-1583. doi:10.1016/j.jfluchem.2006.08.006

14. Kinoshita, K.; Yamada, S.; Iwama, S.; Kawasaki-Takasuka, T.; Yamazaki, T. 20th International Symposium on Fluorine Chemistry, Kyoto, Japan, July 22-27, 2012; Abstr., No. P-41. 
15. Shi, X.; Li, C.-J. Adv. Synth. Catal. 2012, 354, 2933-2938. doi:10.1002/adsc.201200690

16. Masusai, C.; Soorukram, D.; Kuhakarn, C.; Tuchinda, P.; Reutrakul, V.; Pohmakotr, M. J. Fluorine Chem. 2013, 154, 37-42. doi:10.1016/j.jfluchem.2013.06.006

17. Xu, L.; Jiang, H.; Hao, J.; Zhao, G. Tetrahedron 2014, 70, 4373-4378. doi:10.1016/j.tet.2014.04.072

18. Egami, H.; Asada, J.; Sato, K.; Hashizume, D.; Kawato, Y.; Hamashima, Y. J. Am. Chem. Soc. 2015, 137, 10132-10135. doi:10.1021/jacs.5b06546

19. Fustero, S.; Moscardó, J.; Sánchez-Rosselló, M.; Rodriguez, E.; Barrio, P. Org. Lett. 2010, 12, 5494-5497. doi:10.1021/ol102341n

20. Prakash, G. K. S.; Krishnamurti, R.; Olah, G. A. J. Am. Chem. Soc. 1989, 111, 393-395. doi:10.1021/ja00183a073

21. Prakash, G. K. S.; Yudin, A. K. Chem. Rev. 1997, 97, 757-786. doi:10.1021/cr9408991

22. Hagiwara, T.; Kobayashi, T.; Fuchikami, T. Nippon Kagaku Kaishi 1997, 869-875. doi:10.1246/nikkashi.1997.869

23. Hagiwara, T.; Kobayashi, T.; Fuchikami, T. Main Group Chem. 1997, 2, 13-15. doi:10.1080/13583149712331338829

24. Brogan, S.; Carter, N. B.; Lam, H. W. Synlett 2010, 615-617. doi:10.1055/s-0029-1219159

25. Du, G.-F.; Xing, F.; Gu, C.-Z.; Dai, B.; He, L. RSC Adv. 2015, 5, 35513-35517. doi:10.1039/C5RA05487G

26. Kitamura, M.; Okhuma, T.; Inoue, S.; Sayo, N.; Kumobayshi, H.; Akutagawa, S.; Ohta, T.; Takaya, H.; Noyori, R. J. Am. Chem. Soc. 1988, 110, 629-631. doi:10.1021/ja00210a070

27. Ramachandran, P. V.; Chen, G.-M.; Brown, H. C. Tetrahedron Lett. 1996, 37, 2205-2208. doi:10.1016/0040-4039(96)00260-2

28. Witulski, B.; Zimmermann, A. Synlett 2002, 1855-1859. doi:10.1055/s-2002-34883

29. Kosaka, M.; Sekiguchi, S.; Naito, J.; Uemura, M.; Kuwahara, S.; Watanabe, M.; Harada, N.; Hiroi, K. Chirality 2005, 17, 218-232. doi:10.1002/chir.20156

30. Chang, H.-T.; Jeganmohan, M.; Cheng, C.-H. Chem. - Eur. J. 2007, 13, 4356-4363. doi:10.1002/chem.200601880

31. Phan, D. H. T.; Kim, B.; Dong, V. M. J. Am. Chem. Soc. 2009, 131, 15608-15609. doi:10.1021/ja907711a

32. Yasukawa, T.; Kobayashi, S. Chem. Lett. 2017, 46, 98-100. doi:10.1246/cl.160862

33. Mizuta, S.; Shibata, N.; Akiti, S.; Fujimoto, H.; Nakamura, S.; Toru, T. Org. Lett. 2007, 9, 3707-3710. doi:10.1021/ol701791r

34. Kawai, H.; Kusuda, A.; Nakamura, S.; Shiro, M.; Shibata, N. Angew. Chem., Int. Ed. 2009, 48, 6324-6327. doi:10.1002/anie.200902457

35. Kawai, H.; Mizuta, S.; Tokunaga, E.; Shibata, N. J. Fluorine Chem. 2013, 152, 46-50. doi:10.1016/j.jluchem.2013.01.032

36. Cai, C.; Chen, T. Preparation method of 3-trifluoromethyl phthalide. Chin. Pat. Appl CN 2016-11198471, Dec 22, 2016.

While this article was in preparation, on May 17, 2017, a related observation using 2-formylbenzoates was reported in the above stated patent.

37. Hamura, T.; Nakayama, R. Chem. Lett. 2013, 42, 1013-1015. doi:10.1246/cl.130398

\section{License and Terms}

This is an Open Access article under the terms of the Creative Commons Attribution License

(http://creativecommons.org/licenses/by/4.0), which permits unrestricted use, distribution, and reproduction in any medium, provided the original work is properly cited.

The license is subject to the Beilstein Journal of Organic Chemistry terms and conditions:

(https://www.beilstein-journals.org/bjoc)

The definitive version of this article is the electronic one which can be found at:

doi:10.3762/bjoc. 14.12 